\title{
Justificativas favoráveis à criação do Tribunal Constitucional Internacional ${ }^{1}$
}

\begin{abstract}
Alexandre Coutinho Pagliarini ${ }^{2}$
Resumo: Este artigo trata do assunto Tribunal Constitucional Internacional. Na Introdução, são expostos os pressupostos constitucionais e internacionais que evidenciam ser possível a criação do referido Tribunal. No desenvolvimento do texto, primeiramente é exposta a doutrina internacionalista pura, sobretudo assentada no pensamento de Hans Kelsen; num segundo momento, os Direitos Humanos são apresentados como substrato material para sustentar o Tribunal a ser criado; na sequência, prova-se que o Tribunal aqui estudado também se ocuparia de controlar a "constitucionalidade internacional" de uma nova ONU.

Palavras Chave: Tribunal Constitucional Internacional; Direitos Humanos; Nova ONU; Controle da Internacional Constitucionalidade.

Abstract: This paper is about the International Constitutional Court. In its Introduction are exposed the constitutional and international assumptions that evidence the possibility of creation of the reported Court. In the development of this text, it is first exposed a pure internationalist doctrine, above all assented on the thought of Hans Kelsen; therefore, Human Rights are presented as being the material substrate to sustain the Court to be created; in the wake, it is proved that the Court here studied would also occupy itself on the matter of the control of an "international constitutionality" to meet a new UN.

Keywords: International Constitutional Court; Human Rights; New UN; Control of the International Constitutionality.
\end{abstract}

\section{Introdução}

Há de se compreender que a Constituição, nascida do exercício do poder constituinte (que não é um poder jurídico), é um instrumento normativo rígido; isso lhe garante supremacia. Os norte-americanos deram início à ideia sistematizada (e implantada) de controle de constitucionalidade, chamando este sistema de difuso (incidental ou concreto). Já os europeus, mediante influência filosófica kantiana (e até socrática, na antiguidade), sobretudo por meio do trabalho de Hans Kelsen, implantaram os tribunais propriamente - e exclusivamente - constitucionais para exercer o que se chama de controle abstrato (direto ou concentrado) de constitucionalidade. Por sua vez, a evolução da experiência brasileira de controle de constitucionalidade levou este país a adotar um modelo híbrido (ou misto), influenciado tanto pelos Estados Unidos quanto pela Europa, sendo certo que na atualidade o papel do Supremo Tribunal Federal (a "Corte Constitucional" brasileira) se revela mais impactante pela forma concentrada de defesa da Constituição.

Para os que defendem a lógica jurídica da Teoria Monista do Direito, então as normas internacionais hão de ser superiores hierarquicamente às normas nacionais, e para assim se pensar há respaldo nos artigos 26 e 27 da Convenção de Viena sobre o Direito dos Tratados. E, de fato, foi com base na ideia de supremacia das normas internacionais (de Direito Internacional Público - DIP) que se multiplicaram nos

\footnotetext{
${ }^{1}$ Artigo inédito escrito para a obra organizada pelo eminente Senhor Professor Doutor Paulo Ferreira da Cunha, em Portugal, sobre a temática do Tribunal Constitucional Internacional.

${ }^{2}$ Pós-Doutor em Direito Constitucional pela Universidade de Lisboa. Doutor e Mestre em Direito do Estado pela PUC/SP. Professor da Uninter (Curitiba, Paraná, Brasil).
} 
séculos XX e XXI Tribunais Internacionais Permanentes e Organizações Internacionais (O.I.).

Especificamente no que tange à União Europeia, positivou-se, a partir das Comunidades, um Direito superior aos Direitos nacionais, chamado Direito Comunitário, que, tanto para a formação da atual União Europeia quanto para nela garantir os Direitos Fundamentais, encontrou respaldo em atuações decisivas da Corte de Luxemburgo e da Corte de Estrasburgo. Em favor dos Direitos Humanos - e em escala mundial -, não se espera atuação diferente do Tribunal Penal Internacional (TPI) e do Conselho de Segurança das Nações Unidas (ONU), principalmente em tempos de terrorismo(s). De facto, o que ocorre na União Europeia é a verificação incontestável não só de um Direito Comunitário europeu, mas, sim, de um verdadeiro Direito Constitucional Material (Substancial) Supranacional Europeu, e prova disso é o Tratado de Lisboa - mesmo que ainda não haja uma Constituição formal para o bloco supranacional chamado União Europeia. Friso e grito: sim, o Tratado de Lisboa é uma Constituição material europeia!

Se há um aspecto que chama a atenção da Teoria Crítica do Direito, este aspecto é o fato de que o que era globalização só econômica se tornou também globalização política e jurídica, sendo por esta razão que se percebe debutante um verdadeiro Direito da Pós-Modernidade, o Direito Constitucional Internacional que privilegia sobretudo as normas de Direitos Humanos, mesmo aquelas contidas em "meras" Declarações (não advindas de tratados internacionais em que se tenha manifestado o consentimento expresso dos Estados, a pacta sunt servanda), resultando isso do que podemos chamar de "Mundo Novo" e implicando isso não só na superação dos alicerces do Estado-nação mas na multiplicação de organismos judiciários (ou decisórios) supranacionais (na União Europeia) e internacionais (no mundo todo). Isso sim pode ser entendido como neoconstitucionalismo ou neointernacionalismo e uma neojurisdição é esperada - e, de certo modo já se vê presente - para operacionalizar a supremacia da Constituição (quando for o caso) e a do novo Direito Internacional.

Adverte-se, desde já - nesta Introdução -, que não cabe neste escrito discutir temas já vistos como ultrapassados pelos autores europeus e pelos bons pensadores dos países protagonistas do Novo Mundo, razão pela qual aqui não há espaço para procedimentalismos, substancialismos, teorias aderentes ao Realismo Jurídico (versus democracia) ou às estéreis discussões sobre a judicialização da política ou acerca dos "Direitos Civis Constitucionais e congêneres". De fato, a noção que se quer passar aqui é a de uma Teoria Crítica que percebe o Direito como um instrumento de modificação não adstrito às fronteiras das normas estatais-nacionais. Assim, fica articulado este texto com a temática do livro "Tribunal Constitucional Internacional", organizado em Portugal pelo insigne jurista Paulo Ferreira da Cunha.

\section{Desenvolvimento de um rol de justificativas em prol do Tribunal Constitucional Internacional}

\section{(a) A DOUTRINA INTERNACIONALISTA PURA $(0$ DIP NA COMUNIDADE INTERNACIONAL)}

Um juiz de uma Corte Permanente Internacional, ao julgar, por exemplo, um litígio entre Estados soberanos, deve aplicar o DIP, e não o direito do Estado "x", nem 
o do "y". Numa comparação, é como age um ministro do Supremo Tribunal Federal brasileiro: em caso de conflito de normas de dois Estados da federação brasileira (Minas Gerais versus Paraná), ele deverá aplicar a Constituição e usá-la para resolver o impasse; aliás, para Sua Excelência, sempre a Constituição será o nexo de validade de todas as outras normas jurídicas produzidas domesticamente. No sentido acima exposto, o DIP sempre terá preponderância hierárquica sobre os direitos nacionais; e tal afirmação, para um internacionalista, é absolutamente provida de lógica; caso contrário, não se terá DIP (ou seja, o DIP não poderá ser considerado como Direito) e não mais serão necessários juízes internacionais, nem as suas respectivas Cortes permanentes. Neste sentido, nas próximas linhas, interessante será entender as lições de Kelsen.

De fato, para Hans Kelsen, o DIP é Direito (ou seja, é um sistema normativo jurídico!), isto porque existe a sanção, ou seja: um ato de força socialmente organizado e autorizado oficialmente pela Comunidade Internacional, ato este que se explicita na represália ou na guerra, significando isto que na hipótese de um Estado ver os seus interesses (Direitos) ofendidos por um outro Estado, o Estado ofendido poderá criar uma situação que, em condições normais, não seria permitida, reagindo, portanto, à violação provocada por este outro Estado. Para o austríaco, a violação dos interesses entre os Estados constitui-se em delito internacional - não se devendo compreender aqui a palavra interesse egoisticamente, mas devendo-se, sim, ler, "interesses entre Estados" como expressão sinônima de Direitos estabelecidos entre Estados e de algum modo violados. A reação ao delito é uma sanção, e a sua aplicação é feita pelo próprio Estado ofendido, por ainda faltar na Comunidade Internacional um órgão que seja encarregado dessa tarefa, como os existentes nas ordens jurídicas nacionais. Caso estejam Estados litigantes, entretanto, inseridos no sistema de uma mesma ordem jurídica - num Tribunal Internacional ou numa Organização Internacional - poder-se-á vislumbrar a aplicação da sanção pelo terceiro ente (o Tribunal Internacional ou a Organização Internacional), e não pelo Estado cujo direito fora violado. Mas a regra é ainda a da falta de centralidade na Comunidade Internacional, isto por conta da inaplicabilidade do conceito de soberania estatal para o DIP. $E$ é justamente esta falta de centralidade que se verifica na Comunidade Internacional que começa a justificar, aqui neste artigo, a criação de um Tribunal Constitucional Internacional.

Lembre-se que, quanto à soberania, entendia realmente Kelsen que era um conceito que, se existisse, só poderia se aplicar ao Direito Internacional Público, e não às dezenas de ordens jurídicas nacionais: ora, de facto, se soberania quer dizer poder total, então é de se perguntar: como pode no mundo haver 193 poderes totais (193 é o número correspondente ao de Estados filiados à $\mathrm{ONU})$ ?

O DIP, então, é uma ordem normativa das condutas humanas, obrigando pessoas, mediata ou imediatamente. Porém, os destinatários imediatos das normas de DIP são só os sujeitos clássicos de DIP (Estados e Organizações Internacionais); os indivíduos são destinatários mediatos, em regra. Kelsen percebe que não há uma centralização da criação e da aplicação do direito na Ordem Jurídica Internacional. Trata-se o DIP, segundo ele, de uma ordem jurídica primitiva, cujo último estágio de evolução tende para a formação de um Estado mundial, nos moldes dos Estados nacionais contemporâneos; a outra saída kelseniana seria a de um mundo sem Estados nacionais; de um modo ou de outro, daí sim falar-se-ia em soberania com rigor científico!

De qualquer modo, conclui Kelsen que o DIP é superior hierarquicamente aos direitos nacionais, razão pela qual se lhe dá a coroa de "rei do Monismo Jurídico", com o DIP no topo de uma só (daí o monismo) ordem jurídica chamada Direito. 
Efetivamente, a tendência, até dos governos que ratificaram a Convenção de Viena sobre o Direito dos Tratados, é a de começarem abrir as suas soberanas portas para o entendimento de que o DIP é superior e deve ser aplicado, implementando-se, assim, maior centralidade ao DIP, e fugindo-se, destarte, do primitivismo denunciado cientificamente por Kelsen. Tal tendência é o que se depreende do preâmbulo da Convenção de Viena sobre o Direito dos Tratados, quando: 1) reconhece a importância cada vez maior dos tratados como fonte do direito internacional e como meio de desenvolver a cooperação pacífica entre as Nações, quaisquer que sejam os seus regimes constitucionais e sociais; 2) constata que os princípios do livre consentimento e da boa-fé e a regra pacta sunt servanda são universais; 3) proclama o respeito universal e efetivo dos direitos do homem e das liberdades fundamentais; 4) afirma que as regras do Direito Internacional Consuetudinário continuarão a reger as questões não reguladas na Convenção de Viena sobre o Direito dos Tratados.

Sobre o Direito Consuetudinário Internacional, quando foi professor da Universidade de Genebra (Institut de Droit International), Kelsen explicou de forma contundentemente clara que a "sua" Norma Hipotética Fundamental era, na realidade, o Droit Coutumier International (Direito Costumeiro Internacional).

Por fim, aos olhos do DIP, para afirmar a superioridade deste sobre os direitos nacionais, assim estatuíram os seguintes dispositivos da Convenção acima comentada:

"Artigo 26. - Pacta sunt servanda: Todo o tratado em vigor vincula as Partes e deve ser por elas cumprido de boa-fé.

Artigo 27. ${ }^{\circ}$ - Direito interno e observância dos tratados: Uma Parte não pode invocar as disposições do seu direito interno para justificar o incumprimento de um tratado".

\section{(b) OS DIREITOS HUMANOS INTERNACIONAIS COMO NORMAS CONSTITUCIONAIS UNIVERSAIS (GLOBAIS, MUNDIAIS, INTERNACIONAIS E/OU SUPRANACIONAIS)}

São várias as razões que induzem os estudiosos de mente aberta a não terem dúvidas sobre a hierarquia constitucional das Declarações e dos Tratados Internacionais de Direitos Humanos. Enumeremo-las:

$1^{\mathbf{a}}$ RAZÃO - a partir da consideração de que a Constituição nasceu, por escrito e formalmente, no final do século XVIII para cumprir a função de estruturar o Estado e a de proclamar e garantir Direitos Fundamentais, só se pode inferir que normas de Direitos Humanos são normas materialmente constitucionais.

$2^{\mathbf{a}}$ RAZÃO - Se se tomar por exemplo e modelo a realidade constitucional brasileira, o Preâmbulo da Carta Magna em vigor (desde 1988) fala em

“(...) assegurar o exercício dos direitos sociais e individuais, a liberdade, a segurança, o bem-estar, o desenvolvimento, a igualdade e a justiça como valores supremos de uma sociedade fraterna (...)".

Sim, aqui estamos a imprimir força normativa ao Preâmbulo de qualquer Constituição pelo simples fato de que sempre exprime a que veio o país! 
Isto significa que, antes de tudo, o Brasil do constituinte de 1988 é um país que deve primar pela observância ampla dos Direitos Fundamentais. Complementam e concretizam o que aqui é dito os artigos $1^{\circ}$, II, III e IV; $3^{\circ}, \mathrm{IV} ; 5^{\circ}, \S 1^{\circ} ; 6^{\circ} ; 7^{\circ} ; 8^{\circ} ; 9^{\circ}$; $10^{\circ} ; 11 ; 12 ; 13 ; 14 ; 15$, dentre vários outros mais específicos plasmados formalmente na Carta. No que tange às relações internacionais do Brasil, quis a Assembleia Nacional Constituinte que este país fosse regido, dentre outros princípios, pelo da prevalência dos Direitos Humanos (art. $4^{\circ}$, II); prevalência... frise-se!

Ainda no desenvolver deste tópico pontual sobra a Constituição brasileira, desejamos aqui apelidar o $\S 2^{\circ}$ do art. $5^{\circ}$ de "janela aberta" para a prevalência dos Direitos Humanos e para a introdução de normas desta espécie no ordenamento jurídico "tupiniquim". Através da interpretação desta normativa, infere-se que o constituinte brasileiro de 1988, humildemente, não desejou fechar o elenco de Direitos Fundamentais somente nos setenta e oito incisos casuísticos do artigo quinto. Deixou, destarte, a "janela aberta" para que também se pudesse considerar como normas de Direitos Humanos as provenientes de princípios constitucionais e de tratados internacionais. Isto significa que a Constituição brasileira criou três edifícios de peso Constitucional para a construção dos Direitos Humanos com a mesma estatura e a mesma eficácia de seu próprio texto formalmente escrito.

No Brasil, os três edifícios constitucionais de Direitos Humanos são:

(a) aqueles elencados enumeradamente na Carta;

(b) os que os intérpretes da Constituição apontarem como decorrentes de princípios constitucionais de Direitos Humanos;

(c) os que forem formalizados em tratados internacionais de que o Brasil fizer parte.

Em análise fria e que privilegia os Direitos Humanos (sejam ele internacionais, ou não), neste estudo pontual sobre a Constituição brasileira se pode afirmar que a Emenda Constitucional (EC) 45 é inconstitucional! Isto porque criou uma dificuldade para os tratados internacionais de Direitos Humanos. A partir da referida emenda, tais tratados passaram a dever tramitar no Congresso Nacional como se emendas constitucionais fossem, e, como é sabido, antes da EC/45, os tratados internacionais tramitavam pelo Congresso necessitando de maioria simples em sua votação única. Ora, criar um caminho - como criou a EC/45 - que dificulte a caracterização e a execução de normas de Direitos Humanos, num país de democracia tardia, é, para além da ignorância, má vontade e violação explícita ao preexistente art. $60, \S 4^{\circ}$, que, em português claro, prescreve que não deve ser objeto de deliberação proposta de emenda tendente a abolir (ou a diminuir o grau de abrangência dos) os Direitos Fundamentais. Entretanto, a EC/45 criou norma formalmente constitucional, e, enquanto não for derrubada pela Corte Suprema (o STF brasileiro), deve ser aplicada.

Daí, pergunta-se: e os tratados de Direitos Humanos que o Brasil ratificou antes da emenda em tela? A resposta é: são normas materialmente constitucionais, do mesmo modo, por tratarem-se de normas de Direitos Humanos; são normas que, na época, seguiram o trâmite que existia (ato jurídico perfeito), o mesmo da votação da lei ordinária, sendo, portanto, tais tratados, perfeitamente aceitáveis como normas de Direitos Humanos de força constitucional porque, apesar de naquele tempo serem votados no Congresso como leis ordinárias, na realidade - em sua substância material 
- veiculavam já aqueles tratados normas materialmente constitucionais por serem tratados de Direitos Humanos.

A afirmação é peremptória: tratados internacionais de Direitos Humanos têm hierarquia constitucional no sistema jurídico brasileiro pelas razões acima expostas.

\section{(c) O TRIBUNAL CONSTITUCIONAL INTERNACIONAL COMO INSTRUMENTAL DE CONTROLE DE CONSTITUCIONALIDADE (INTERNACIONAL) DAS NORMAS ESTRUTURANTES DA COMUNIDADE JURÍDICA INTERNACIONAL, MAIS ESPECIFICAMENTE DAS NAÇÕES UNIDAS (ONU)}

É certo - e assim ficou demonstrado acima - que os Direitos Humanos se constituiriam num dos dois pilares da atuação de um futuro Tribunal Constitucional Internacional, isso porque as normas de Direitos Humanos fazem parte do constitucionalismo moderno desde o advento da Constituição escrita nos fins do século XVIII, assim como têm sido os Direitos Humanos Fundamentais tema recorrente do Direito Internacional Público. Daí, pergunta-se: ora, se os Direitos Humanos são um dos dois pilares do constitucionalismo internacional, qual seria o outro pilar?

Em resposta à pergunta acima lançada, assumimos que o segundo papel (ou pilar) do Direito Constitucional Internacional deve ser o de estruturar o mundo por intermédio da recriação da Organização das Nações Unidas (ONU). E como se reestruturaria a ONU? A resposta é: pela democracia representativa! E do seguinte modo: cada um dos 193 Estados soberanos hoje existentes no mundo teria dois âmbitos de representação na ONU, quais sejam: (i) um equivalente ao Senado de um Estado federal - como o Brasil -, com, por exemplo, dois ou três representantes, independentemente da sua densidade populacional, de modo que China e Paraguai teriam o mesmo número de representantes destes dois Estados; (ii) outro representativo do povo de cada um dos 193 Estados soberanos hoje existentes na Comunidade Internacional, proporcional ao número de eleitores de cada um desses países, estabelecendo-se, evidentemente, um número máximo e um número mínimo de representantes.

Do modo sucintamente descrito no parágrafo anterior, ter-se-ia um órgão político internacional (a ONU) reestruturado e democrático, e isso, indubitavelmente, seria substrato material para a criação efetiva de um Tribunal Constitucional Internacional que, por funções, seria a Corte Mundial de controle de constitucionalidade das normas estruturantes da nova ONU (a verdadeira e reformulada Cosmópolis) e das normas internacionais de Direitos Humanos, todas elas - as normas estruturantes e as de Direitos humanos - superiores hierarquicamente às normas domésticas dos 193 países-membros da ONU.

\section{Conclusões}

A globalização era só econômica; mas, há tempos, ela se tornou também globalização política e jurídica, sendo por esta razão que se percebe debutante um verdadeiro Direito da Pós-Modernidade, o Direito Constitucional Internacional; daí a necessidade de um Tribunal Constitucional Internacional, o qual que seria (i) o 
guardião da estrutura da Cosmópolis ONU e que (ii) privilegiaria, essencialmente, as normas de Direitos Humanos, mesmo aquelas contidas em Declarações (não advindas de tratados internacionais, soft law...???). Resulta tal possibilidade jurídica do admirável "Mundo Novo" e implica isso não só na superação dos alicerces do Estadonação, mas na multiplicação de organismos judiciários (ou decisórios) supranacionais (na União Europeia) e internacionais (no mundo todo, neste caso pelas mãos da ONU).

Fica apresentado aos leitores deste livro o que hodiernamente pode - com trunfos científicos! - ser entendido como Neoconstitucionalismo ou Neointernacionalismo, e uma Neojurisdição é esperada e já se vê presente - para operacionalizar a supremacia do Direito Constitucional Internacional.

À guisa de conclusão, afirmamos que o Direito Internacional deve se mostrar como um Direito superior - e isto deve ser garantido pelos Tribunais Internacionais e aceito pelos Estados! -, senão ele (o DIP) sempre estará sujeito aos unilateralismos das Constituições e dos Estados.

De toda sorte, ambos - Direito Internacional e Direito Constitucional - muito mais se aproximam na TGD (Teoria Geral do Direito) do que se afastam, e disso não temos dúvida uma vez que ambos organizam ora a Polis, ora a Cosmópolis, e na polis (ou na Cosmópolis) definem e garantem Direitos Humanos.

Há que se tomar posição: portanto, opinamos pela superioridade hierárquica do Direito Constitucional Internacional, e oxalá seja ela garantida pelas jurisdições! Gritamos, outrossim por imediatas conversações convergentes para a criação do Tribunal Constitucional Internacional, Corte esta que - repita-se! - cumpriria dois papéis: $1^{\circ}$ - ela seria a guardiã dos Direitos Fundamentais internacionais; $2^{\circ}$ - ela seria a guardiã de uma nova e reestruturada ONU (Cosmópolis).

\section{Bibliografia referencial}

FAVOREU, Louis. As cortes constitucionais. São Paulo: Landy. 2004.

GIDDENS, Anthony. Mundo em descontrole - O que a globalização está fazendo de nós. Rio de Janeiro: Editora Record, 2007.

HABERMAS, Jürgen. Après l'État Nation. Paris: Fayard, 2008.

HABERMAS, Jürgen. Era das transições. Rio de Janeiro: Edições Tempo Brasileiro, 2001.

LEBEN, Charles. Hans Kelsen: écrits français de droit international. Paris: PUF, 2001.

MACHADO, Jónatas, E. M. Direito internacional do paradigma clássico ao pós-11 de setembro. 4. ed. Coimbra: Coimbra Editora, 2013. 
PAgliARINI, Alexandre Coutinho; CHOUKR, Fauzi Hassan. Cooperação jurídica internacional. Belo Horizonte: Editora Fórum, 2014.

PFERSMANN, Otto. Positivismo jurídico e justiça constitucional no século XXI. 1. ed. Tradução: Alexandre Coutinho Pagliarini. Prefácio: Jorge Miranda: Apresentação: Francisco Rezek. São Paulo: Saraiva, 2014.

Recebido para publicação em 05-09-15; aceito em 02-10-15 